Article

\title{
Energetic and Exergetic Analysis of Low Global Warming Potential Refrigerants as Substitutes for R410A in Ground Source Heat Pumps
}

\author{
Sergio Bobbo ${ }^{1, *}$, Laura Fedele ${ }^{1}$ (D), Marco Curcio ${ }^{1,2}$, Anna Bet $^{1}$, Michele De Carli ${ }^{2}$, \\ Giuseppe Emmi ${ }^{2}$ (D) Fabio Poletto ${ }^{3}$, Andrea Tarabotti ${ }^{3}$, Dimitris Mendrinos ${ }^{4}$, \\ Giulia Mezzasalma ${ }^{5}$ and Adriana Bernardi ${ }^{6}$ \\ 1 Istituto per le Tecnologie della Costruzione, Consiglio Nazionale delle Ricerche, I-35127 Padova, Italy; \\ laura.fedele@itc.cnr.it (L.F.); la.rufanzia@gmail.com (M.C.); anna.bet@itc.cnr.it (A.B.) \\ 2 Dipartimento di Ingegneria Industriale, Università degli Studi di Padova, I-35131 Padua, Italy; \\ michele.decarli@unipd.it (M.D.C.); giuseppe.emmi@unipd.it (G.E.) \\ 3 Hi-Ref S.p.A., I-35020 Tribano, Italy; fabio.poletto@hiref.it (F.P.); andrea.tarabotti@hiref.it (A.T.) \\ 4 Geothermal Energy Department, Centre for Renewable Energy Sources and Saving, 19009 Pikermi, Greece; \\ dmendrin@cres.gr \\ 5 RED Srl. Via le dell'Industria 58B, I-35127 Padova, Italy; giulia.mezzasalma@red-srl.com \\ 6 Istituto di Scienze dell'Atmosfera e del Clima, Consiglio Nazionale delle Ricerche, I-35127 Padova, Italy; \\ adriana.bernardi@isac.cnr.it \\ * Correspondence: sergio.bobbo@itc.cnr.it
}

Received: 1 July 2019; Accepted: 7 September 2019; Published: 16 September 2019

check for updates

\begin{abstract}
In the European Union (EU), buildings are responsible for about $40 \%$ of the total final energy consumption, and $36 \%$ of the European global $\mathrm{CO}_{2}$ emissions. The European Commission released directives to push for the enhancement of the buildings energy performance and identified, beside the retrofit of the current building stock, Heating, Ventilation, and Air Conditioning (HVAC) systems as the other main way to increase renewable energy sharing and overall building energy efficiency. For this purpose, Ground Source Heat Pumps (GSHPs) represent one of the most interesting technologies to provide energy for heating, cooling, and domestic water production in residential applications, ensuring a significant reduction (e.g., up to $44 \%$ compared with air-source heat pumps) of energy consumption and the corresponding emissions. At present, GSHPs mainly employ the refrigerant R410A as the working fluid, which has a Global Warming Potential (GWP) of 2087. However, following the EU Regulation No. 517/2014 on fluorinated greenhouse gases, this high GWP refrigerant will have to be substituted for residential applications in the next years. Thus, to increase the sustainability of GSHPs, it is necessary to identify short time alternative fluids with lower GWP, before finding medium-long term solutions characterized by very low GWP. This is one of the tasks of the UE project "Most Easy, Efficient, and Low-Cost Geothermal Systems for Retrofitting Civil and Historical Buildings" (acronym GEO4CIVHIC). Here, a thorough thermodynamic analysis, based on both energy and exergy analysis, will be presented to perform a comparison between different fluids as substitutes for R410A, considered as the benchmark for GSHP applications. These fluids have been selected considering their lower flammability with respect to hydrocarbons (mainly R290), that is one of the main concerns for the companies. A parametric analysis has been performed, for a reversible GSHP cycle, at various heat source and sink conditions, with the aim to identify the fluid giving the best energetic performance and to evaluate the distribution of the irreversibilities along the cycle. Considering all these factors, R454B turned out to be the most suitable fluid to use in a ground source heat pump, working at given conditions. Special attention has been paid to the compression phase and the heat transfer in evaporator and condenser.
\end{abstract}

Keywords: ground source heat pumps; low GWP refrigerants; energy analysis; R410A; R32; R454B 


\section{Introduction}

In 2018 almost 12 million heat pumps were installed across Europe, and a large number of these were installed in Italy and France [1]. It should be stressed that this number accounts for just over $10 \%$ of operating heating systems and that gas boilers still occupy the majority of the market. Yet such a market is not sustainable from an environmental point of view. In this instance, according to EU Regulations [2,3], heat pumps come forward as an increasingly important player because they represent one of the main solutions in the direction to use more renewable energy for heating and cooling [4]. However, the application of Ground Source installations in the built environment is not well developed [5]. Previous studies were mainly focused on Air Source Heat Pumps and on refrigerant alternatives.

In the last two decades, the market of refrigerants has been dominated by hydrofluorocarbons (HFCs), which represent the biggest share of fluorinated greenhouse gases. As HFCs have a relatively high GWP and thus contribute to global warming when released into the atmosphere, the recent EU Regulation 517/2014 imposes a strong reduction of their total quantity to be marketed in the next 15 years, down to $20 \%$ of their annual marketed volume, compared to the year 2014 [6]. For instance, as a first step, starting from 2015, HFCs with GWP > 150 have been banned in domestic refrigerators [6].

This led to high prices of HFCs, urging the industry to find economically and environmentally sustainable alternatives of low GWP [7].

According to the type of application, different working fluids can be used in refrigeration cycles and the selection of the most suitable depends on practical and commercial purposes. Within the heat pumps and chillers sector, HFCs that are being replaced are basically R134a and R410A [8,9]. With a GWP respectively of 1043 and 2088, they are the most common high GWP refrigerants used at present. Their replacement is being undertaken to limit and control their emissions that contribute to global warming and climate change. Considering the best combination of cooling capacity and coefficient of performance (COP) results, Mota-Babiloni et al. [10] analyzed different HFC/HFO mixtures and showed good results for N-13, XP-10, and ARM-42A when substituting R134a, L41, and DR-5 as good alternative refrigerants to R410A.

In order to replace R410A, pure R32 was introduced in domestic air conditioners as a short-term option during the last couple of years. Despite being an HFC, R32 is characterized by much lower GWP than R410A (675 instead of 2088) and by only $\frac{1}{4}$ of the refrigerant charge needed for the same heating or cooling power output. Mota-Babiloni et al. [11] investigated its use in air conditioning and heat pump systems, confirming its slightly higher performance than R410A in terms of cooling and heating modes.

In the context of high temperature HPs, using R717, R365mfc, R1234ze(E), and R1234ze(Z) [12] and R1233zd(E) and 1336mzz(Z) [13], Kondou and Koyama [12] and Mateu-Royo et al. [13] evaluated the theoretical performance of different cycle configurations with hydrofluoroolefines in order to demonstrate the potential use of high temperature HPs to recover waste heat and reduce the primary energy consumption.

One of the task of the European Project GEO4CIVHIC is to analyze the possible HFCs alternatives suitable for the applications in the context of ground source heat pumps with domestic heating and cooling purposes. In doing that, many criteria have to be met, such as suitable thermodynamic properties, low flammability and toxicity, and stability in the system [14]. Merely substituting R410A with a lower GWP is not enough, because if the lower GWP refrigerant does not yield good performance in the system, it can lead to increased energy consumption, and thus to greater indirect emissions [15].

$\mathrm{Wu}$ and Skye [16] presented a survey on GSHPs using $\mathrm{CO}_{2}, \mathrm{NH}_{3}$, water, and hydrocarbons and evaluated advantages and disadvantages of natural refrigerants in terms of thermodynamic characteristics, operation in vapor compression GSHPs, and also flammability and toxicity. The parameter study presented by Aisyah et al. [17] is the first one that correlates an exergy and energy analysis of a heat pump system using R1224yd to the effect on the environment. 
However, research on proper refrigerant to replace R410A in GSHPs for building heating, under varied ground conditions, is sparse. Researches on GSHPs are mainly related to GSHP design guidance and heat exchanger simulations [18,19] or to system application effects and control strategies [20,21]. The most common type of ground heat exchanger is the Borehole Heat Exchanger (BHE), a vertical pipe loop reaching depths of 50-200 $\mathrm{m}[22,23]$.

In this paper, the results of an analysis comparing short-term alternatives characterized by intermediate GWP $(<1000)$ are reported, with the aim to identify transition solutions to be applied by EU companies in the period necessary to identify suitable refrigerants with very limited GWP $(<150)$, that is the final goal to get low-environmental impact HPs. The selected transition fluid will be used within the project in a prototype and tested in a demo site. What it is expected from this analysis is to establish the most suitable fluid to be checked in pilot facilities. Moreover, it is expected that the solution that this study provides would allow Europe to increase its competiveness and assert its leadership in the field of Ground Source systems.

\section{Methodological Approach of the Study}

The purpose of this study is to simulate and compare the thermodynamic behavior of present and moderate GWP refrigerants in a reversible GSHP. Model simulation, carried out using Matlab software [24], was applied to predict the performance of the system under certain working conditions, besides irreversibilities in each component. Thermodynamic properties of fluids were calculated through Refprop 10.0 Database [25].

\subsection{Refrigerant Selection}

In this work, R410A was taken as the reference refrigerant and its performance in thermodynamic cycles were compared with those of alternative refrigerants. For its replacement, substitutes have to obtain the best compromise between energy efficiency and volumetric refrigeration capacity. Considering these factors, R32 and R454B were chosen as the most promising potential substitutes for R410A [26]. Both can be considered as transition solutions characterized by intermediate-GWP. According to the ASHRAE refrigerant classification standard, they are classified as A2L: low toxic and mildly flammable with burning velocities less than $10 \mathrm{~cm} \cdot \mathrm{s}^{-1}$ [27]. Their basic characteristics are given in Table 1.

Table 1. Basic characteristics of the selected fluids according to Refprop 10.0.

\begin{tabular}{cccccccc}
\hline Fluid & GWP & $\begin{array}{c}\text { ASHRAE Safety } \\
\text { Class [27] }\end{array}$ & Composition (wt \%) & $T_{\text {crit }}(\mathbf{K})$ & $\begin{array}{c}\boldsymbol{P}_{\text {crit }} \\
\text { (Mpa) }\end{array}$ & $\begin{array}{c}\text { T Glide } \\
\text { (K) }\end{array}$ & NPB (K) \\
\hline R410A & 2088 & A1 & R32/R125 (50/50) & 343.32 & 4.770 & 0.05 & 212.15 \\
R32 & 675 & A2L & R32 (100) & 351.55 & 5.816 & - & 221.15 \\
R454B & 466 & A2L & R32/R1234yf (68.9/31.1) & 350.15 & 5.041 & 1.5 & 222.25 \\
\hline
\end{tabular}

\subsection{Assumptions for the Thermodynamic Cycle}

A simple vapor compression refrigeration system was considered to simulate the heat pump in heating mode. The system with the main components (compressor, condenser, expansion valve, and evaporator) is schematically shown in Figure 1. Secondary fluids are water in both heat exchangers, when temperature is above $0{ }^{\circ} \mathrm{C}$. In case of low temperature of the fluid in the ground loops, secondary fluid in the evaporator is a brine (mixture of water and propylene glycol at fixed concentration of $30 \%$ ).

The main goal of this work is studying GSHPs for retrofitting civil and historical buildings, with different low and high temperature terminals for heating. Since they have to be suitable for all buildings, climates and ground conditions considered in the project, different operating temperatures for the user and for the ground source were set to evaluate the thermodynamic performance. 


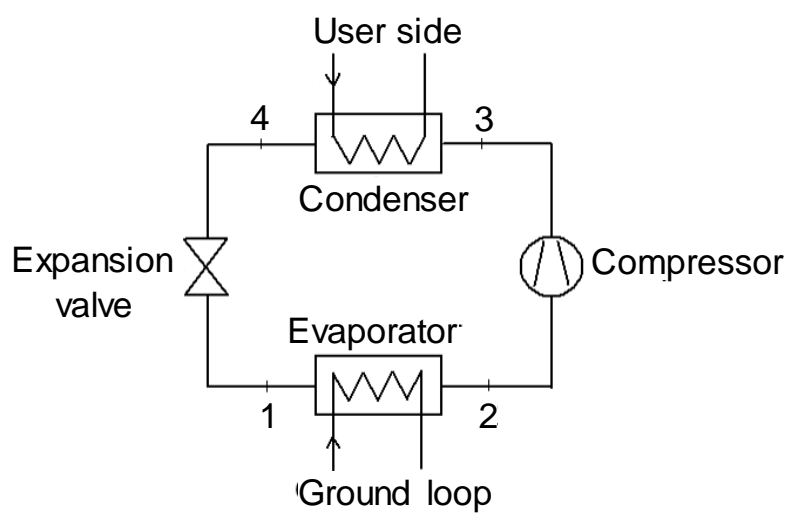

Figure 1. Layout of the heat pump system.

In relation to the ground loop, the temperatures of the heat carrier fluids can be variable depending on several factors like location, ground stratification, type of technology, and number and depth of the vertical ground source heat exchangers [28]. Furthermore, during the years of operation of the GSHP system, the temperatures could be very different if the boreholes field is not properly designed and the ground is affected by the so-called thermal drift [29].

Temperature differences of the secondary fluids through the heat exchangers were fixed, corresponding to typical values for heat pump already present in the market [30]. All the assumed system parameters and boundary conditions are specified in Section 2.6.

To model the heat exchangers (condenser and evaporator) a pinch analysis was applied. Pinch point position, i.e. the position in a heat exchanger where the temperature profiles of the fluids have the minimum temperature difference, is important to analyze heat transfer in thermodynamic cycle and it has to be determined accurately [31,32]. A very small minimum temperature difference between the temperature profiles of the fluids may cause an increase in costs, because much larger heat exchange surface areas are necessary. At the same time, bigger minimum temperature difference between the profiles increases exergetic losses in the heat transfer, thus decreasing the energy efficiency of the system. Pinch point position depends on the slope of the fluids temperature profile and on the superheating and subcooling assumed for the refrigerant. In the simulations, on the base of the assumptions made, the pinch point in the condenser is located at the inlet of the primary fluid; in the evaporator, it is located at the outlet of the primary fluid. These values are defined in Section 2.6.

In order to minimize irreversibilities associated with temperature difference, heat exchangers present a counter-current configuration of the fluids. This feature allows a better coupling between the temperature profiles and less exergetic losses. Considering the aims of the study, in this work, heat exchangers are considered as ideal, assuming a unit value for efficiency and no heat losses and pressure drops. An isenthalpic process was assumed for the expansion device, while a relatively complex procedure was followed to assume the isentropic efficiency of the compressor, as described in the next section.

\section{Compressor}

In order to accurately determine the performance of the thermodynamic cycle, isentropic efficiency of the compressor was carefully analyzed. As is well known, it represents the ratio between the work input to an isentropic process and the work input to the actual process, at the same inlet and exit pressures. Two approaches were considered to establish the influence of the isentropic efficiency on the cycle performance.

As a first step of the analysis, a constant value of the isentropic efficiency was assumed: this hypothesis ensures a fair comparison of the performances of different fluids, considering the same efficiency for all fluids and for all the working conditions. 
The second step, more realistic, considered a variable isentropic efficiency, depending on the fluid, the selected commercial compressor and the working conditions. A scroll compressor (Bitzer GSU60120VL, Sindelfingen, Germany) available in the market and optimized for refrigerants R410A, R32, R454B, (and also R452B) was chosen, depending on the typical size of the GSHPs studied in the project. Working with this compressor at given conditions, each fluid has a different isentropic efficiency. The discharge temperatures were obtained through the Bitzer free online software 6.9 [33] and, indirectly, the isentropic efficiency was derived. This second approach helps to understand the different quality of the compression work and the heat losses occurring during the actual compression process, considering a real compressor present in the market.

Figure 2 shows the isentropic efficiency values for each fluid as a function of the user outlet temperature, i.e. the temperature of the secondary fluid at condenser outlet, once all the other boundary conditions are fixed. Assuming a constant value of the isentropic efficiency (Ref. line in Figure 2) for all fluids and all working conditions may lead to a not realistic evaluation of the compressor performance and therefore of the global performance of the thermodynamic cycle. Moreover, this assumption may cause a wrong selection of the most suitable refrigerant for a specific application with given working conditions.

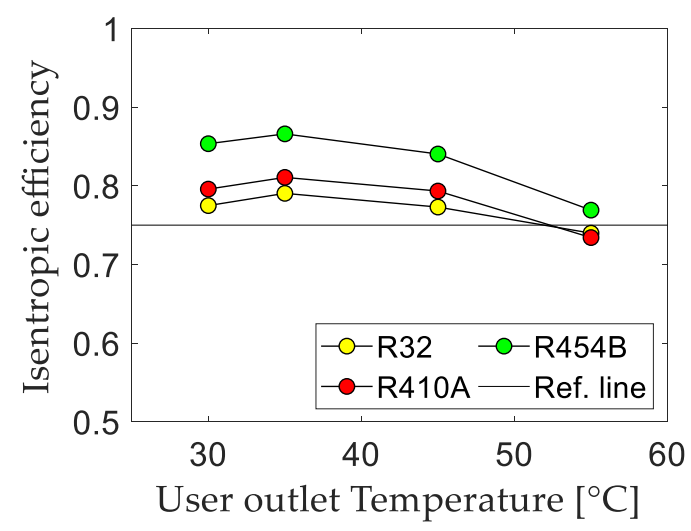

Figure 2. Constant value and actual values of isentropic efficiency at given boundary conditions calculated for the Bitzer GSU60120VL compressor.

\subsection{Regenerative Cycle}

With the aim to improve the performance of the base thermodynamic cycle, the addition of a liquid-line/suction-line heat exchanger (LLSL-HX) was evaluated. Thanks to the intra-cycle exchanger, the high-pressure refrigerant from the condenser is subcooled by the low pressure vapor entering the compressor [34]. This configuration is shown in Figure 3, with the description of the cycle in the P-h diagram.

As well known in the literature, high molecular mass fluids can take advantage from the regeneration because of their lower negative or their positive slope of vapor saturation curve in $T$-s diagram [35]. Subcooling of high-pressure liquid and superheating of low pressure vapor depend on the amount of heat transferred in the LLSL-HX. The maximum advantage is obtained considering a flooded evaporator, in which the refrigerant is not fully evaporated. Here, a two-phase mixture with 0.9 vapor quality has been considered as leaving low pressure fluid, where the vapor quality is defined from thermodynamics as the ratio between the vapor mass and the total mass of the mixture. The evaporation process is thus completed, together with the superheating of the vapor, in the LLSL-HX. The main benefit of this solution consists in a higher evaporation temperature and therefore in a reduction of the pressure ratio and of the compressor work. 


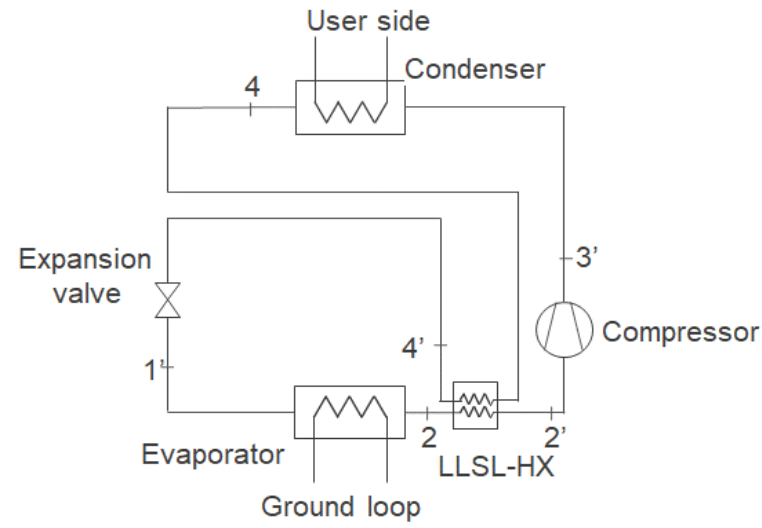

(a)

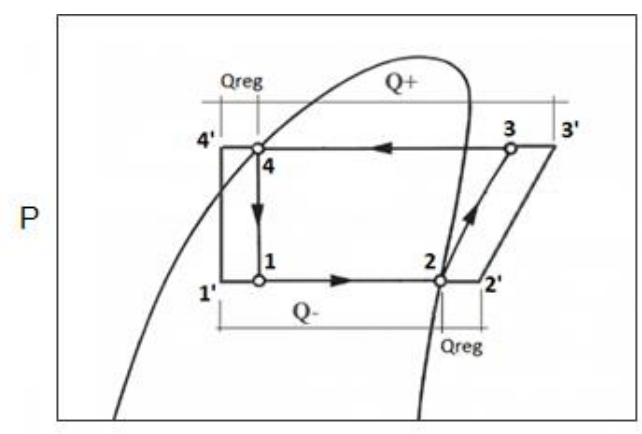

h

(b)

Figure 3. Compression cycle with (a) liquid-line/suction-line heat exchanger (LLSL-HX) and (b) the corresponding pressure-enthalpy diagram [36].

\subsection{Energy Analysis}

To evaluate the performance of the thermodynamic cycle, an energy analysis was carried out. Isentropic efficiency was calculated as follows (see Figure 2):

$$
\eta_{i s}=\left(h_{3 i s}-h_{2}\right) /\left(h_{3}-h_{2}\right)
$$

where $h_{3 i s}$ and $h_{3}$ are the enthalpies at compressor discharge, respectively for isentropic and real compression, $h_{2}$ is the enthalpy at compressor suction.

Volumetric Heating Effect is another interesting parameter that represents the refrigerating effect per unit of swept volume. It provides information about the heat pump dimensions and about the required refrigerant charge.

$$
\mathrm{VHE}=\Delta h / v
$$

where $\Delta h$ is the enthalpy variation at the condenser and $v$ is the refrigerant specific volume at compressor inlet.

The main energetic parameter used to compare the refrigerants efficiency is the coefficient of performance (COP) of the heat pump cycle, defined as the ratio between the heat supplied from the cycle to the hot reservoir $\left(\dot{Q}_{c o n d}\right)$ and the required network input at the compressor $\left(\dot{W}_{c}\right)$ :

$$
\mathrm{COP}=\dot{Q}_{\text {cond }} / \dot{W}_{c}
$$

where $\dot{Q}_{\text {cond }}$ represents the power absorbed by the working fluid at the condenser, exchanged with the user and set at $7000 \mathrm{~W}$ for every working condition.

The compressor power input $\dot{W}_{c}$ is calculated as follows:

$$
\dot{W}_{c}=\dot{m}_{r e f}\left(h_{3}-h_{2}\right)
$$

where $\dot{m}_{r e f}$ is the refrigerant mass flow rate, which is known from the power exchanged at the condenser and the enthalpy difference at the condenser, $h_{3}$ is the enthalpy at compressor discharge and $h_{2}$ is the enthalpy at compressor suction.

\subsection{Exergy Analysis}

For a more comprehensive comparison of the refrigerant's performance, a detailed exergy analysis has been performed applying the general exergy theory described, e.g., in Reference [37]. This type of analysis allows to evaluate thermodynamic processes identifying the major sources of irreversibilities 
and then inefficiencies in energy exploitation. The optimization of a thermodynamic process has the purpose to minimize exergy losses, whereas energy, according to the first law of thermodynamics, cannot be destroyed and then no information on the quality of each thermodynamic process can be derived by energy balances. The overall system exergetic efficiency can be defined as follows:

$$
\eta_{e x}=\dot{E}_{u s e f u l} / \dot{W}_{c}
$$

where $\dot{E}_{u s e f u l}$ is the output exergy flux, i.e. the exergy absorbed by the user secondary fluid, and $\dot{W}_{c}$ is the input exergy flux to the system, supplied through the compression work.

The exergy absorbed by the user secondary fluid $\dot{E}_{\text {useful }}$ is obtained as:

$$
\dot{E}_{\text {useful }}=\dot{m}_{\text {user }}\left(k_{u \_o u t}-k_{u \_i n}\right)
$$

where $\dot{m}_{\text {user }}$ is the user flow rate of the secondary loop and $k_{u_{\_} \text {out }}$ and $k_{u_{\_} i n}$ are the specific coenthalpies of the user fluid at the exit and at the entrance of the condenser. Coenthalpy is the potential of exergy flow and it is defined as:

$$
k=h-T_{a} \cdot s
$$

where $T a$ is a reference temperature, set at $5{ }^{\circ} \mathrm{C}$ and $h$ and $s$ are respectively the enthalpy and the entropy of the working fluid at the heat exchanger.

For each thermodynamic process in the cycle, exergy losses were calculated to evaluate their relative contribute to system energy efficiency. Exergy losses were calculated using the following equations:

$$
\begin{array}{lll}
\text { - } & \text { compressor } \quad L_{\text {comp }}=\dot{W}_{c}-\dot{m}_{\text {ref }}\left(k_{3}-k_{2}\right) \\
\text { - } & \text { condenser } \quad L_{\text {cond }}=\dot{m}_{\text {ref }}\left(k_{3}-k_{4}\right)-\dot{m}_{\text {user }}\left(k_{u \_ \text {out }}-k_{u \_ \text {in }}\right) \\
\text { - } & \text { evaporator } \quad L_{\text {evap }}=\dot{m}_{\text {ground }}\left(k_{\text {g_out }}-k_{\text {g_in }}\right)-\dot{m}_{\text {ref }}\left(k_{1}-k_{2}\right) \\
\text { - } & \text { throttling valve } \quad L_{\text {valve }}=\dot{m}_{\text {ref }}\left(k_{4}-k_{1}\right) \\
\text { - } & \text { LLSL-HX } \left.\quad L_{L L S L-H X}=\dot{m}_{\text {ref }}\left(k_{4}-k_{4}{ }^{\prime}\right)-\left(k_{2}{ }^{\prime}-k_{2}\right)\right]
\end{array}
$$

where $\dot{m}_{g}$ is the water flow rate of the ground loop, got from the balances, and $k_{g_{-}}$out and $k_{g_{-} \text {in }}$ are the specific coenthalpies of the geothermal fluid at the exit and at the entrance of the evaporator.

\subsection{Assumed System Parameters}

The following assumptions have been made during the analysis:

- $\quad$ exchanged power at the condenser set at 7000 Watt.

- $\quad$ superheating at evaporator outlet should be as low as possible, but higher than zero to prevent liquid entering the compressor. Hence, a constant value of $6 \mathrm{~K}$ was assumed.

- subcooling in the condenser is another design parameter, fixed at $5 \mathrm{~K}$.

- $\quad$ Pinch Point temperature difference $\Delta t_{p p}=3^{\circ} \mathrm{C}$.

Simulations were run by varying both inlet and outlet temperature of the ground heat source (evaporator) and the user (condenser) secondary fluids (Table 2).

Table 2. Working conditions of the secondary fluids.

\begin{tabular}{ccccc}
\hline Conditions & $\begin{array}{c}\text { Inlet Evaporator } \\
\text { Temperature }\left({ }^{\circ} \mathbf{C}\right)\end{array}$ & $\begin{array}{c}\text { Outlet Evaporator } \\
\text { Temperature }\left({ }^{\circ} \mathbf{C}\right)\end{array}$ & $\begin{array}{c}\text { Inlet Condenser } \\
\text { Temperature }\left({ }^{\circ} \mathbf{C}\right)\end{array}$ & $\begin{array}{c}\text { Outlet Condenser } \\
\text { Temperature }\left({ }^{\circ} \mathbf{C}\right)\end{array}$ \\
\hline 1 & 0 & -3 & 25 & 30 \\
2 & 3 & 0 & 30 & 35 \\
3 & 7 & 4 & 40 & 45 \\
4 & 10 & 7 & 50 & 55 \\
\hline
\end{tabular}




\section{Results and Discussion}

The main results of the analysis are summarized below and compare the performance of the thermodynamic cycle using R410A and those of the potential alternative fluids R32 and R454B. Diagrams are referred to the extreme working conditions for the secondary fluid circulating in the ground loop, i.e. inlet/outlet temperatures $\left(T_{g}\right)$ at the evaporator:

- $\quad T_{g}=0 /-3^{\circ} \mathrm{C}$

- $\quad T_{g}=10 / 7^{\circ} \mathrm{C}$

For these two sets of secondary fluid temperatures, performance of the heat pump producing domestic water at 4 different user secondary fluid outlet temperatures (from 30 to $55^{\circ} \mathrm{C}$ ) are shown.

\subsection{Base Configuration}

\subsubsection{Isentropic Efficiency of the Compressor}

Considering that isentropic efficiency is different for each fluid and working condition, as came out from previous analysis, it affects the performance of the thermodynamic cycle in different way. Figure 4 shows that compressor isentropic efficiency has a similar trend but, at the same time, different values for each fluid. R454B is the fluid that can guarantee the highest isentropic efficiency at all user temperatures.

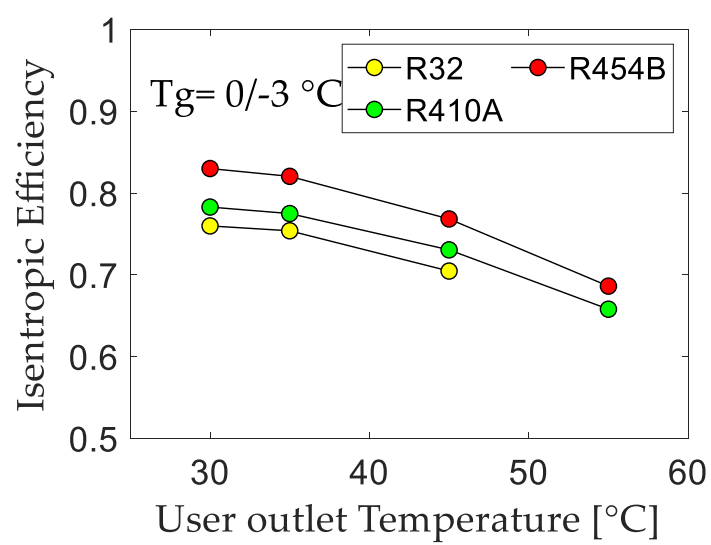

(a)

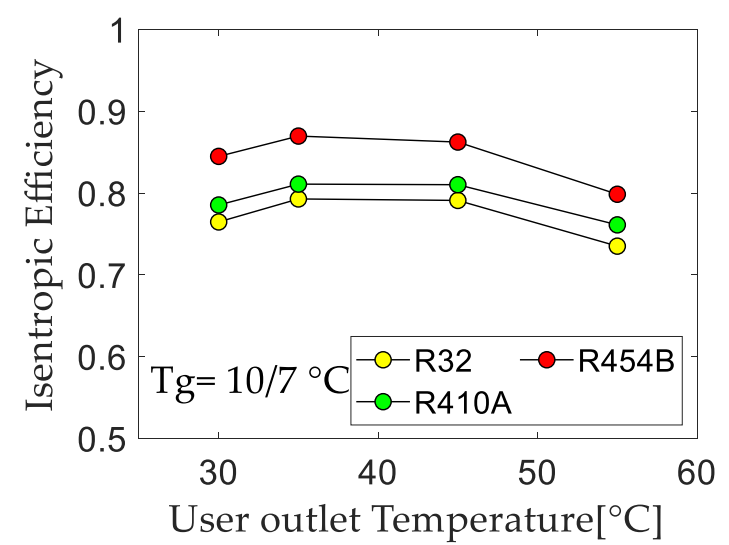

(b)

Figure 4. Isentropic Efficiency. (a) $T_{g}=0 /-3^{\circ} \mathrm{C}$; (b) $T_{g}=10 / 7^{\circ} \mathrm{C}$

It is also interesting to notice how the shape of trends is different for different temperature levels of the heat carrier fluid of the ground loop $\left(T_{g}\right)$. This variation depends on the nominal design limits of the compressor and is due to the fact that when compressor works with too high or too small pressure ratio, the efficiency of the compression process decreases.

\subsubsection{Coefficient of Performance (COP)}

Figure 5 shows that, for both extreme working temperature levels of the ground loop secondary fluid, COP decreases with the increasing of the user secondary fluid outlet temperature at the condenser, as expected due to the increase of pressure ratio. For the same reason, $\mathrm{COP}$ is lower when $T_{g}=0 /-3^{\circ} \mathrm{C}$ than when $T_{g}=10 / 7^{\circ} \mathrm{C}$, considering all other conditions fixed. 


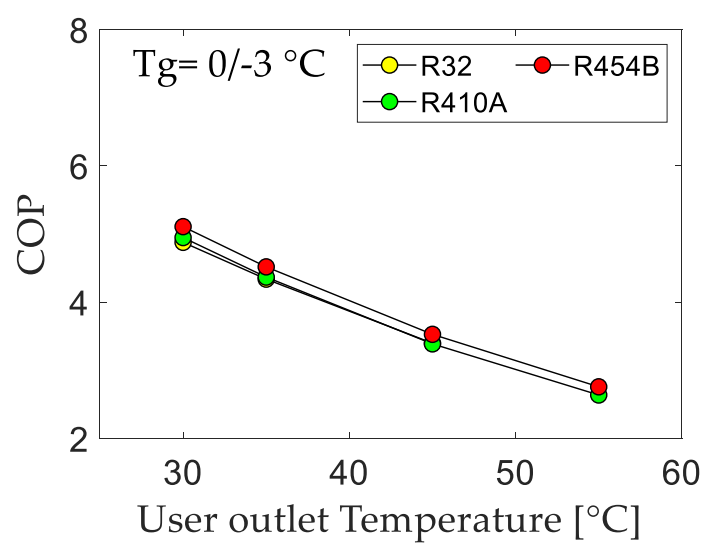

(a)

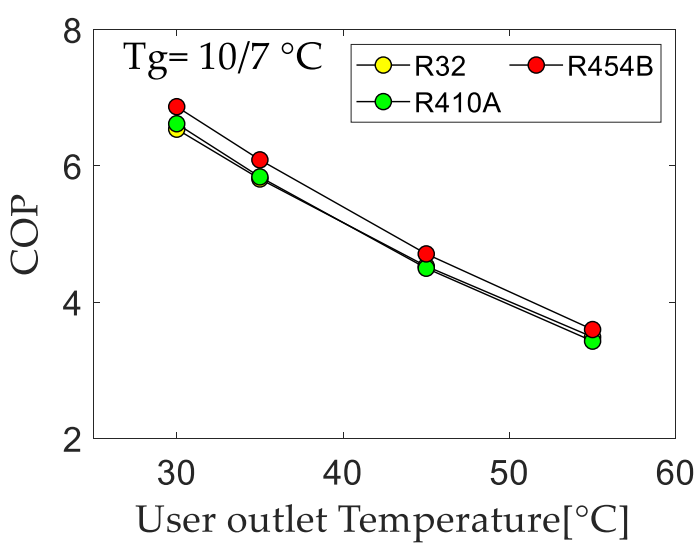

(b)

Figure 5. Coefficient of performance (COP). (a) $T_{g}=0 /-3{ }^{\circ} \mathrm{C}$; (b) $T_{g}=10 / 7^{\circ} \mathrm{C}$

R454B has slightly higher (around 5\%) COP than R32 and R410A (similar each other) in all working conditions.

\subsubsection{Volumetric Heating Effect (VHE)}

The results of the VHE are summarized in Figure 6. As it can be seen, R32 has the highest VHE. Thus, it needs lower volumetric flow rate than the other fluids to exchange the same thermal power. $\mathrm{R} 454 \mathrm{~B}$, vice versa, has the smallest value of the volumetric heating effect because it is a mixture of HFC R32 and HFO R1234yf having relatively low density. R410A has an intermediate behavior. It is interesting to note that the trend of VHE for each fluid is almost independent from the user secondary fluid outlet temperature at the condenser, that is from the pressure ratio. The trend of the volumetric heating effect is very important because it gives information about the required volumetric mass flow rate and therefore about the size of the heat pump and pipes.

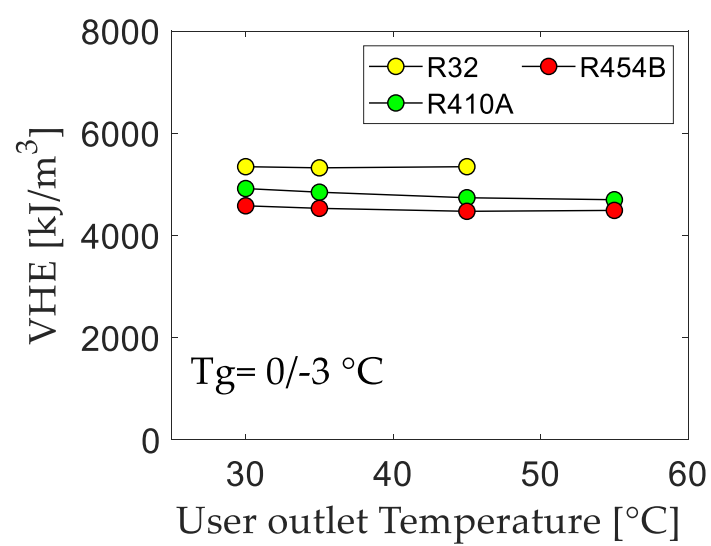

(a)

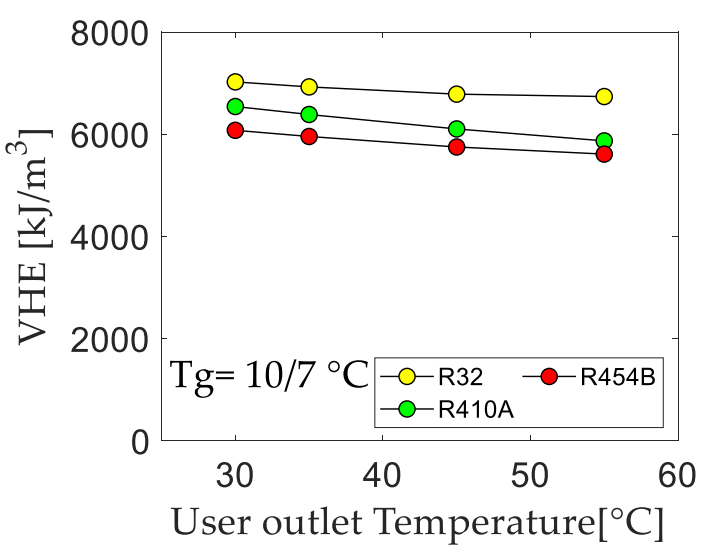

(b)

Figure 6. Volumetric heating effect. (a) $T_{g}=0 /-3{ }^{\circ} \mathrm{C}$; (b) $T_{g}=10 / 7{ }^{\circ} \mathrm{C}$

\subsubsection{Exergetic Efficiency}

Exergetic efficiency trend is shown in Figure 7. As for the isentropic efficiency, the value is higher for higher temperatures of the ground loop fluid. R454B always stands as the refrigerant with the best performance, as from first law analysis. The trend of the performance is not linear because exergetic efficiency of components influences the heat transfer process differently according to the working temperatures. 


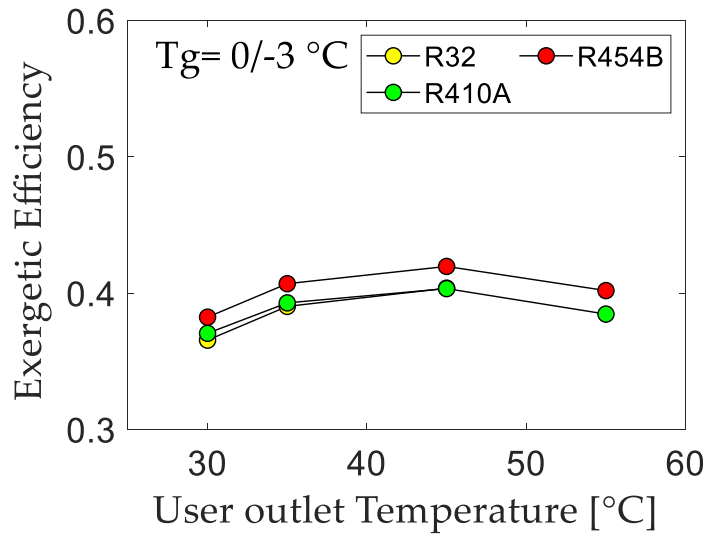

(a)

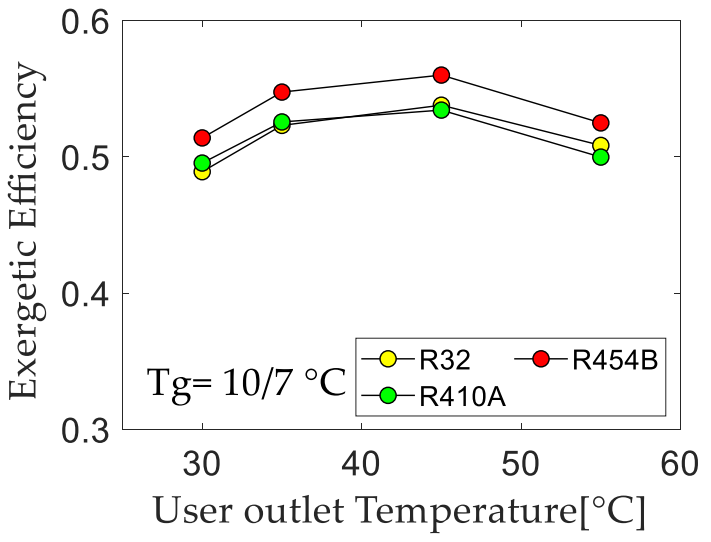

(b)

Figure 7. Exergetic Efficiency. (a) $T_{g}=0 /-3^{\circ} \mathrm{C}$; (b) $T_{g}=10 / 7^{\circ} \mathrm{C}$.

\subsubsection{Exergetic Losses}

Exergetic analysis is useful because it allows to evaluate the distribution of exergetic losses and thus the inefficiencies of the heat pump components. Figure 8 shows what are the exergy losses generated in each component of the heat pump at a specific condenser condition for the lowest and the highest working temperature levels at the evaporator. In the case of $T_{g}=0 /-3{ }^{\circ} \mathrm{C}$, it is evident that compression is the thermodynamic process with the highest exergy losses, followed by throttling. Even for the case with the highest evaporation temperatures $\left(T_{g}=10 / 7^{\circ} \mathrm{C}\right)$, and thus the lowest temperature difference between evaporation and condensation temperatures, compression and throttling are the worst processes, even if with lower differences from condensation and evaporation. Amongst the three refrigerants here considered, R454B showed total exergy losses lower than the other fluids: this result is mainly due to the much lower exergy losses in the compression process. In general, to improve the overall efficiency of the heat pump, efforts should be addressed to improve the efficiency of compression and throttling processes.

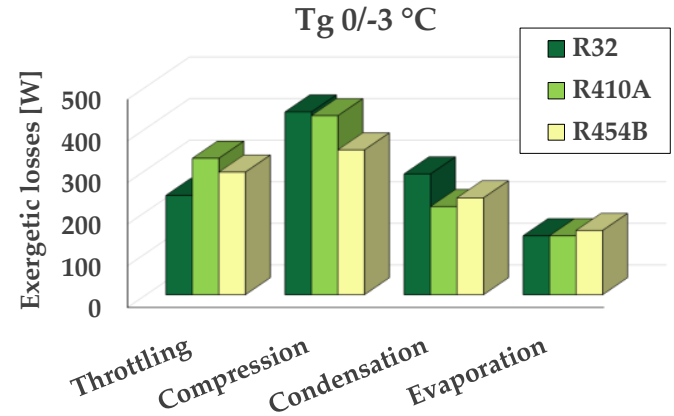

(a)

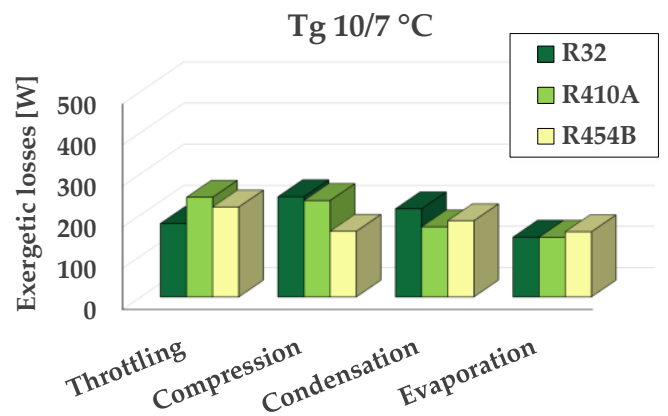

(b)

Figure 8. Exergy losses generated in the heat pump components considering inlet condenser temperature $40^{\circ} \mathrm{C}$ and outlet condenser temperature $45^{\circ} \mathrm{C}$. (a) $T_{g}=0 /-3{ }^{\circ} \mathrm{C}$; (b) $T_{g}=10 / 7^{\circ} \mathrm{C}$.

\subsection{Regenerative Configuration}

Regenerative configuration can increase the performance of the base cycle, depending on fluid and working conditions. In this configuration, a vapour quality of 0.9 was assumed for the working fluid at evaporator outlet. Then, the refrigerant moves to the LLSL heat exchanger, where it completes the evaporation and exits $5^{\circ} \mathrm{C}$ superheated.

The consequences at the evaporator are:

- $\quad$ pinch point moves at refrigerant inlet in the evaporator; 
- $\quad$ evaporation temperature increases;

- $\quad$ temperature profiles are closer (Figure 9).

When the conditions are favorable, regeneration process allows to decrease exergetic losses and compression work. At the same time, it can improve the performance of thermodynamic cycle. In relation to isentropic efficiency, regeneration is not necessarily beneficial, because the reduction of the pressure ratio induced by the evaporating temperature increase is not always positive for the compression efficiency. However, compression efficiency worsening is less significant than compression work reduction and thus the overall effect can be positive.

Regenerative cycle performance is represented in terms of percentage deviation from the base cycle performance. Figures 10 and 11 highlight that regenerative configuration is beneficial for all fluids in every working condition in terms of both COP and exergetic efficiency. This means that using LLSL-HX improves energy performance in all cases and then is strongly suggested for these fluids and operative conditions. While R32 and R410A have similar improvement with respect to the base case, the increase of COP and exergetic efficiency is more evident for R454B with respect to the other fluids.

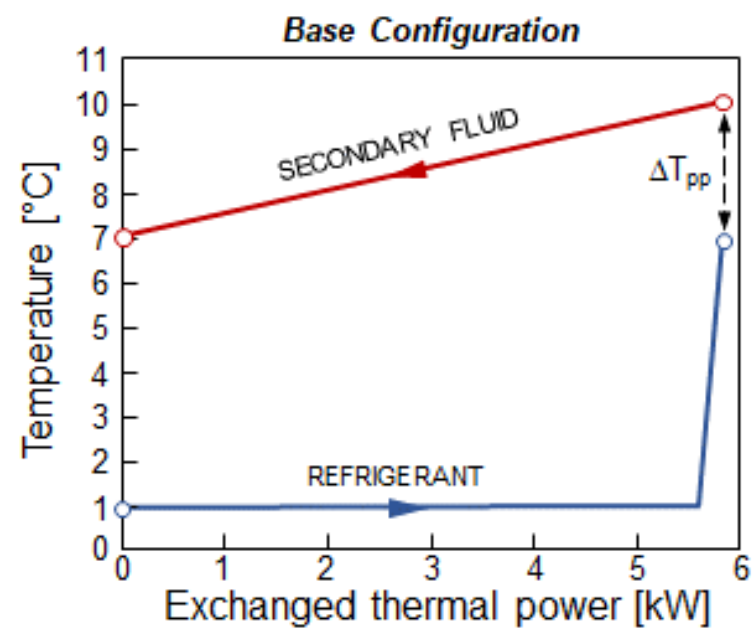

(a)

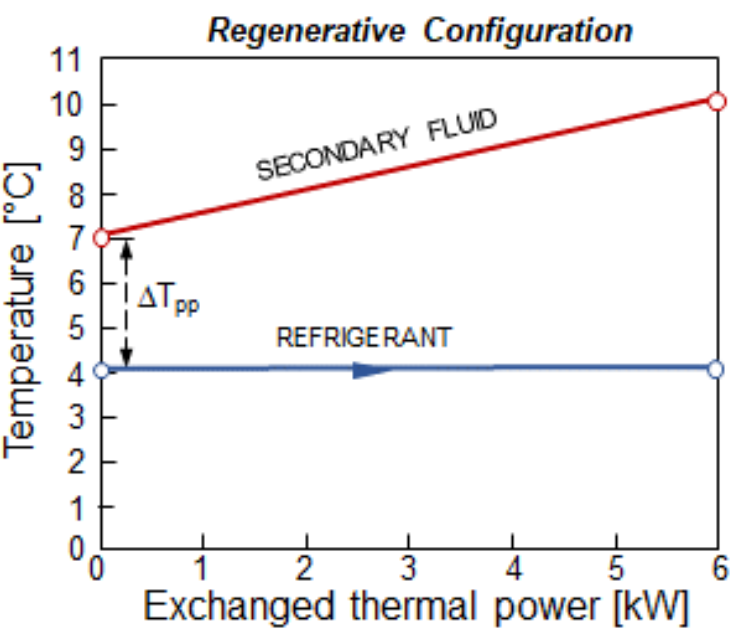

(b)

Figure 9. Temperature profiles in the evaporator for the two thermodynamic cycles. (a) Base Configuration; (b) Regenerative Configuration.

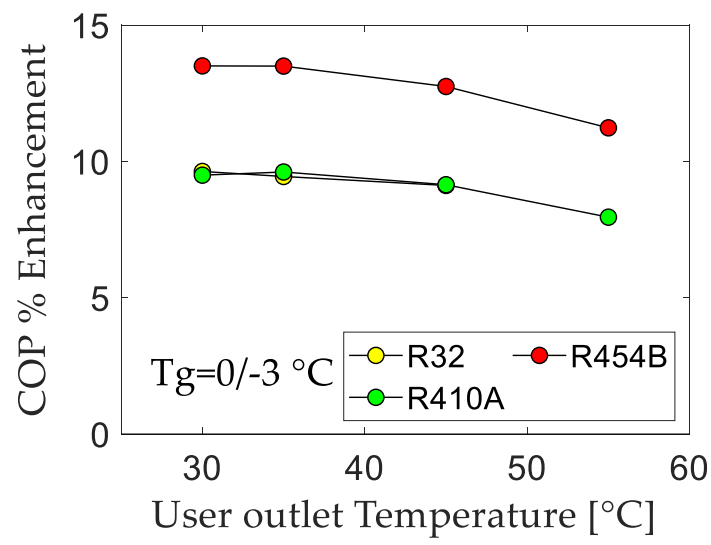

(a)

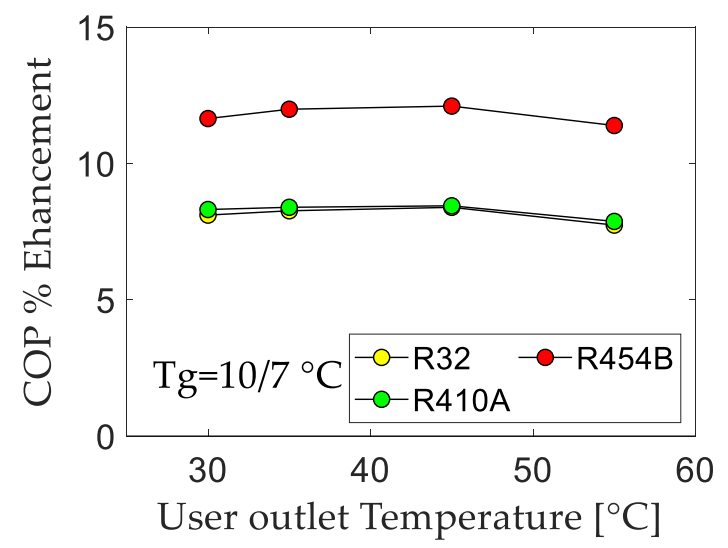

(b)

Figure 10. Percentage deviation of coefficient of performance (COP). (a) $T_{g}=0 /-3^{\circ} \mathrm{C} ;(\mathbf{b}) T_{g}=10 / 7^{\circ} \mathrm{C}$. 


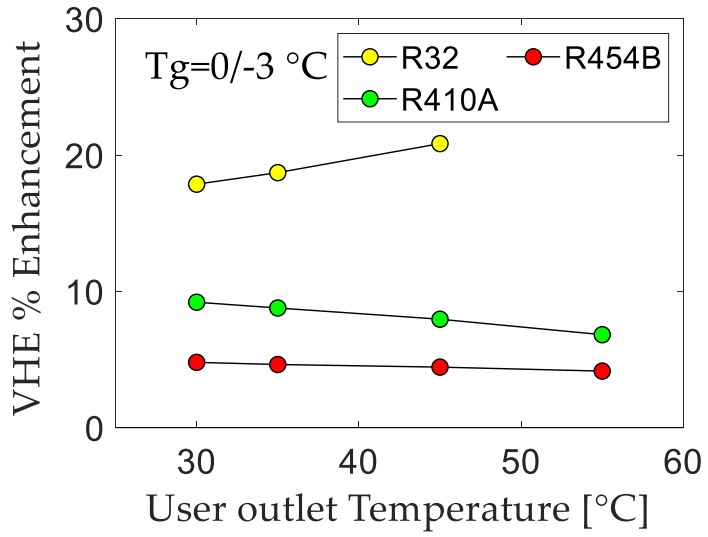

(a)

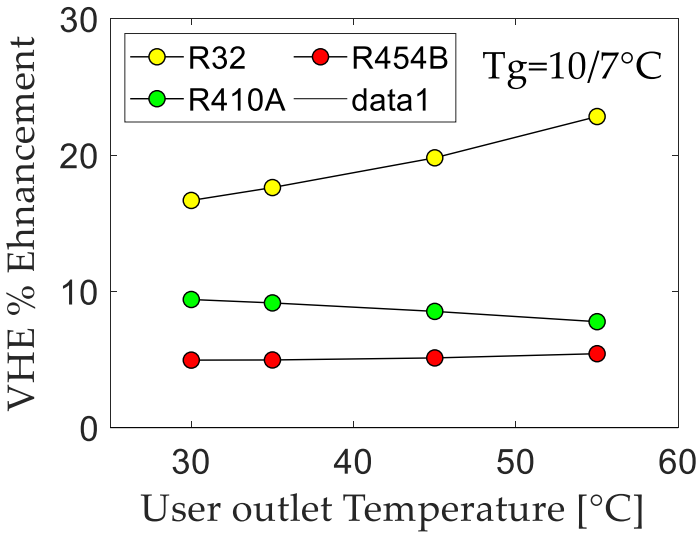

(b)

Figure 11. Percentage deviation of the Volumetric Heating Effect. (a) $T_{g}=0 /-3{ }^{\circ} \mathrm{C} ;(\mathbf{b}) T_{g}=10 / 7^{\circ} \mathrm{C}$.

The regenerative configuration leads also to increased VHE, as represented in Figure 11. In relation to VHE, R32 has the highest benefit with respect to the other refrigerants.

\subsubsection{Exergetic Efficiency}

As for the previous factors, exergetic efficiency benefits from the regenerative configuration as well. The increase of exergetic efficiency compared to the base cycle occurs for every fluid and every working temperature (Figure 12). Once again, R454B is the refrigerant that gets the most profit.

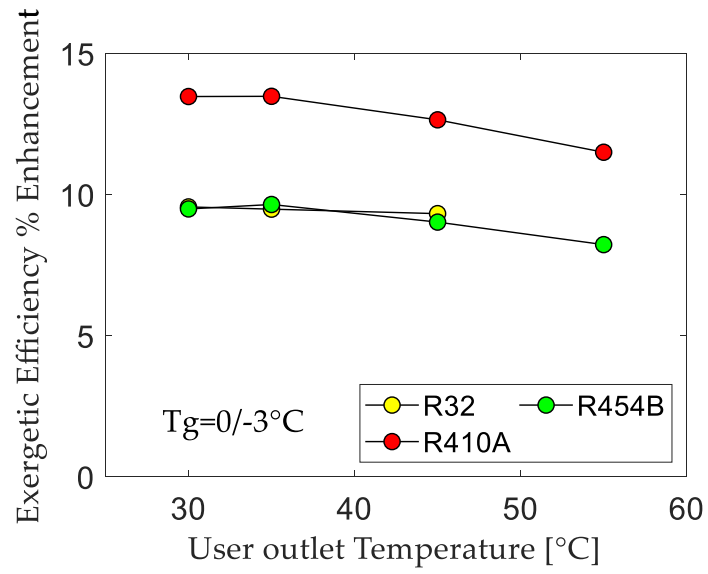

(a)

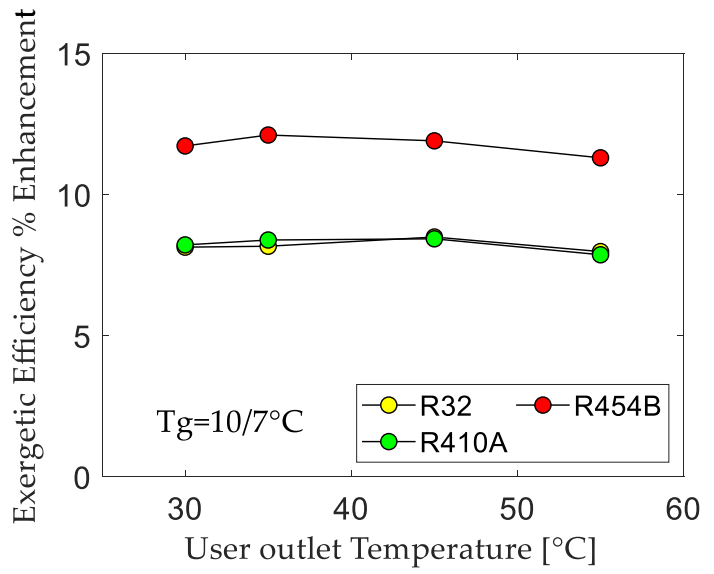

(b)

Figure 12. Percentage deviation of the exergetic efficiency. (a) $T_{g}=0 /-3{ }^{\circ} \mathrm{C}$; (b) $T_{g}=10 / 7^{\circ} \mathrm{C}$.

\subsubsection{Exergetic Losses}

The regenerative configuration allows to reduce some exergetic losses of the system, represented in Figure 13. Comparing Figures 8 and 13, a considerable reduction during the throttling and evaporation phase is noticeable.

During the evaporation process, losses decrease depending on the change of position of the pinch point. Since the pinch point moves at refrigerant inlet in the evaporator, the area between the two temperature profiles is greatly reduced, and the losses decrease (see Figure 9).

Throttling losses are reduced both because of the increase of evaporation temperature and because of the higher subcooling of liquid at the entrance of the valve. 


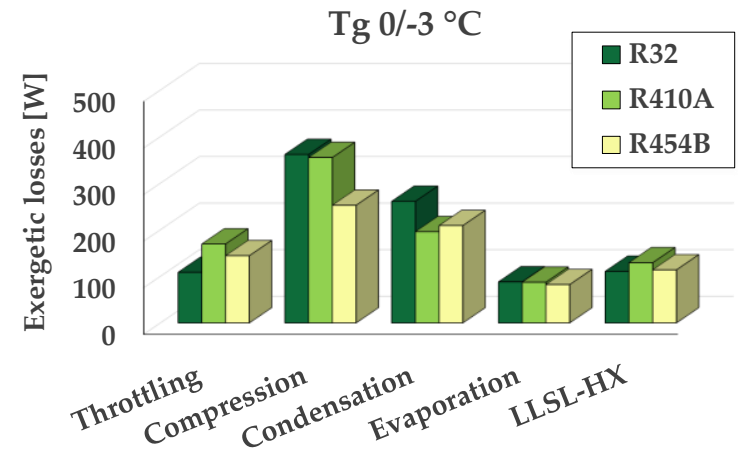

(a)

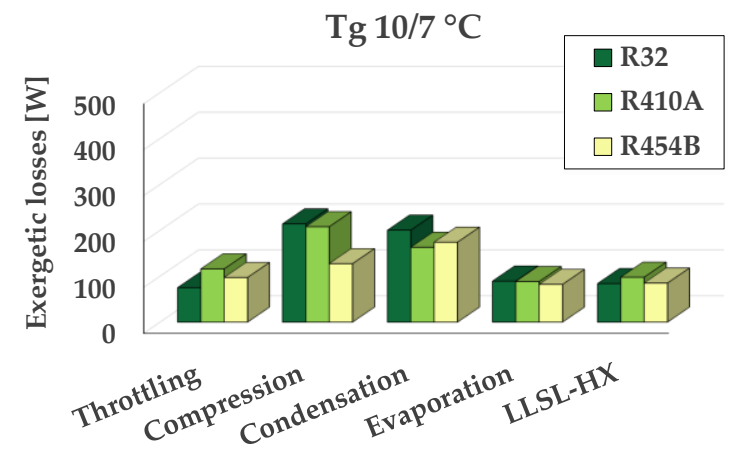

(b)

Figure 13. Exergy losses generated in the heat pump components, included liquid-line/suction-line heat exchanger (LLSL-HX), considering inlet condenser temperature $40^{\circ} \mathrm{C}$ and outlet condenser temperature $45^{\circ} \mathrm{C}$. (a) $T_{g}=0 /-3{ }^{\circ} \mathrm{C}$; (b) $T_{g}=10 / 7{ }^{\circ} \mathrm{C}$.

It also important to notice that the decrease varies according to the refrigerant and the complexity of the molecules.

Despite the fact that all the losses tend to decrease, it should be considered that in the regenerative configuration there is an additional exchanger, also characterized by exergetic losses. However, these losses do not give an important contribution to the total exergetic losses of the system.

\section{Conclusions}

As there are many factors influencing the performance of a thermodynamic cycle, it is necessary to carry out an overall analysis to identify the best refrigerant, amongst those with intermediate GWP $(<1000)$, for the replacement of R410A in ground source heat pumps. Thus, a comprehensive analysis has been performed considering the first and the second laws of thermodynamics, as well as exergetic losses in the various components, compressor discharge temperature, and volumetric heating effect.

From the compressor point of view, the analysis has been performed considering both the case of fixed isentropic efficiency for all the considered refrigerants (R410A, R32 and R454B) and that of variable isentropic efficiency as calculated from a software reproducing the behavior of a commercial compressor working with all the considered refrigerants. It is interesting to note that the two approaches gave totally different results. In particular, in the more realistic case of variable isentropic efficiency, R454B showed to be the most promising refrigerant. Thus, assuming constant isentropic efficiency, even if in principle correct from the thermodynamic point of view, can be misleading with respect to the actual performance in a commercial compressor.

A comparison between base configuration and regenerative configuration of the cycle has also been performed, with the aim to evaluate the opportunity to install a LLSL-HX in the cycle. Significantly higher values of COP and exergetic efficiency than R410 and R32 are obtained with R454B in both cases, but with clear enhancements induced by the presence of the LLSL-HX with respect to the base configuration of the cycle.

Vice versa, R454B is characterized by a lower volumetric heating effect than R410A and R32. This can implicate a bigger size of components of the heat pump (e.g., compressor) and then higher costs. For sure, more studies and research have to be made in relation to R454B, which is basically unknown from the technical point of view, since the first compressors using this fluid have been produced in 2018. Moreover, R454B is a zeotropic mixture: therefore, it requests attention in heat exchangers optimization, since variations of the refrigerant temperature and composition can occur during the operation. Finally, in terms of flammability, it is classified as an A2L refrigerant: thus, the mass charged in the system should be limited, preventing use in large installations.

It is also important to underline that the analysis here performed is based on ideal assumptions (for example, effect of the pressure losses was not considered here) that could affect the results, if 
applied in real installations. The results found, however, provide a starting point for the selection of intermediate GWP replacement fluids.

Author Contributions: Conceptualization: S.B. and L.F.; Methodology: S.B., M.D.C. and M.C.; Software: M.C., A.T. and A.B. (Anna Bet); Validation: M.D.C., G.E. and D.M.; Formal Analysis: M.C. and A.B. (Anna Bet).; Investigation: M.C., A.B. (Anna Bet) and S.B.; Resources: F.P. and L.F.; Data Curation: G.M.; Writing-Original Draft Preparation: S.B., A.B. (Anna Bet) and M.C.; Writing-Review \& Editing: S.B. and A.B. (Anna Bet); Visualization: S.B. and A.B. (Anna Bet); Supervision: M.D.C.; Project Administration: S.B. and L.F.; Funding Acquisition: A.B. (Adriana Bernardi).

Funding: This research was funded by Horizon 2020 (792355) and the APC was funded by ITC CNR.

Acknowledgments: The present study is realized within the project "Most Easy, Efficient and Low Cost Geothermal Systems for Retrofitting Civil and Historical Buildings" (Grant agreement ID: 792355) of the European Union's Horizon 2020 research and innovation program.

Conflicts of Interest: The authors declare no conflict of interest. The funders had no role in the design of the study; in the collection, analyses, or interpretation of data; in the writing of the manuscript, and in the decision to publish the results.

\section{Nomenclature}

$\begin{array}{lll}\text { COP } & \text { Coefficient of performance } & - \\ G W P & \text { Greenhouse Warming Potential } & - \\ \dot{E}_{\text {useful }} & \text { Exergy output } & \mathrm{W} \\ h & \text { Enthalpy } & \mathrm{J} / \mathrm{kg} \\ H F O & \text { Hydrofluoroolefin } & - \\ H P & \text { Heat pump } & - \\ H V A C & \text { Heating, Ventilation and Air Conditioning } & - \\ k & \text { Coenthalpy } & \mathrm{J} / \mathrm{kg} \\ L & \text { Exergetic Loss } & \mathrm{W} \\ L L S L-H X & \text { Liquid line/suction line heat exchanger } & - \\ \dot{m}_{g} & \text { Water flow rate of the ground loop } & \mathrm{kg} / \mathrm{s} \\ \dot{m}_{r e f} & \text { Refrigerant mass flow rate } & \mathrm{kg} / \mathrm{s} \\ \dot{m}_{\text {user }} & \text { User mass flow rate } & \mathrm{kg} / \mathrm{s} \\ s & \text { Entropy } & \mathrm{J} / \mathrm{kg} \cdot \mathrm{K} \\ T_{a} & \text { Air temperature } & { }^{\circ} \mathrm{C} \\ V H E & \text { Volumetric heating effect } & \mathrm{kJ} / \mathrm{m}^{3} \\ v & \text { Specific volume } & \mathrm{m}{ }^{3} / \mathrm{kg} \\ \dot{Q}_{\text {cond }} & \text { Power at the condenser } & \mathrm{W} \\ T_{g} & \text { Water or brine temperature in the ground loop } & { }^{\circ} \mathrm{C} \\ \dot{W}_{c} & \text { Compressor power consumption } & \mathrm{W} \\ \text { Greek Symbols } & & \\ \eta_{i s} & \text { Isentropic efficiency of the compressor } & - \\ \eta_{e x} & \text { Exergetic efficiency } & - \\ S u b s c r i p t s & & \\ p p & \text { Pinch point } & \\ & & \end{array}$

\section{References}

1. Nowak, T.; Westring, P. European Heat Pump Market and Statistics Report; The European Heat Pump Association AISBL (EHPA): Brussels, Belgium, 2018.

2. Council, E. Directive 2010/31/EU of the European Parliament and of the Council of 19 May 2010 on the energy performances of buildings. Off. J. Eur. Union 2010, 153, 13-35.

3. Directive (EU) 2018/844 of the European Parliament and of the Council of 30 May 2018 amending Directive 2010/31/EU on the energy performance of buildings and Directive 2012/27/EU on energy efficiency. Available online: https:/eur-lex.europa.eu/legal-content/EN/TXT/PDF/?uri=CELEX:32018L0844\&from=EN (accessed on 14 January 2019). 
4. Bianco, V.; Scarpa, F.; Tagliafico, L. Estimation of primary energy savings by using heat pumps for heating purposes in the residential sector. Appl. Therm. Eng. 2017, 114, 938-947. [CrossRef]

5. Sanner, B.; Dumas, P.; Gavriliuc, R.; Zeghici, R. The use of geothermal energy for buildings refurbishment in Europe-technologies, success stories and perspectives. Rev. Romana Inginerie Civila 2013, 4, 183.

6. Directive (EU) 2014/517 of the European Parliament and of the Council of 16 April 2014 on fluorinated greenhouse gases and repealing Regulation (EC) 2006/842. Available online: https://eur-lex.europa.eu/legalcontent/EN/TXT/PDF/?uri=CELEX:32014R0517\&from=EN (accessed on 14 January 2019).

7. Mota-Babiloni, A. Analysis of low Global Warming Potential fluoride working fluids in vapour compression systems. Experimental evaluation of commercial refrigeration alternatives. Ph.D. Thesis, Jaume I University, Castellón de la Plana, Spain, 2016.

8. McLinden, M.O.; Kazakov, A.F.; Brown, J.S.; Domanski, P. A thermodynamic analysis of refrigerants: Possibilities and tradeoffs for Low-GWP refrigerants. Int. J. Refrig. 2014, 38, 80-92. [CrossRef]

9. Botticella, F.; De Rossi, F.; Mauro, A.W.; Vanoli, G.P.; Viscito, L. Multi-criteria (thermodynamic, economic and environmental) analysis of possible design options for residential heating split systems working with low GWP refrigerants. Int. J. Refrig. 2017, 87, 131-153. [CrossRef]

10. Mota-Babiloni, A.; Navarro-Esbrı, J.; Barragan-Cervera, A.; Moles, F.; Peris, B. Analysis based on EU Regulation No 517/2014 of new HFC/HFO mixtures as alternatives of high GWP refrigerants in refrigeration and HVAC systems. Int. J. Refrig. 2015, 52, 21-31. [CrossRef]

11. Mota-Babiloni, A.; Navarro-Esbr1, J.; Makhnatch, P.; Moles, F. Refrigerant R32 as lower GWP working fluid in residential air conditioning systems in Europe and the USA. Renew. Sustain. Energy Rev. 2017, 80, 1031-1042. [CrossRef]

12. Kondou, C.; Koyama, S. Thermodynamic assessment of high-temperature heat pumps using Low-GWP HFO refrigerants for heat recovery. Int. J. Refrig. 2015, 53, 126-141. [CrossRef]

13. Mateu-Royo, C.; Navarro-Esbrı, J.; Mota-Babiloni, A.; Amat-Albuixech, M.; Moles, F. Theoretical evaluation of different high-temperature heat pump configurations for low-grade waste heat recovery. Int. J. Refrig. 2018, 90, 229-237. [CrossRef]

14. Bobbo, S.; Di Nicola, G.; Zilio, C.; Brown, J.S.; Fedele, L. Low GWP halocarbon refrigerants: a review of thermophysical properties. Int. J. Refrig. 2018, 90, 181-201. [CrossRef]

15. Makhnatch, P.; Khodabandeha, R. The role of environmental metrics (GWP, TEWI, LCCP) in the selection of low GWP refrigerant. Energy Procedia 2014, 61, 2460-2463. [CrossRef]

16. Wu, W.; Skye, H. Progress in Ground Source Heat Pumps using natural refrigerants. Int. J. Refrig. 2018, 92, 70-85. [CrossRef] [PubMed]

17. Aisyah, N.; Alhmaid, M.I.; Nasruddin, S.; Lubis, A.; Saito, K. Parametric study and multi-objective optimization of vapor compression heat pump system by using environmental friendly refrigerant. J. Adv. Res. Fluid Mech. Therm. Sci. 2019, 54, 44-56.

18. Nam, Y.; Chae, H.B. Numerical simulation for the optimum design of ground source heat pump system using building foundation as horizontal heat exchanger. Energy 2014, 73, 933-942. [CrossRef]

19. Li, H.; Nagano, K.; Lai, Y.; Shibata, K.; Fujiimoto, H. Evaluating the performance of a large borehole ground source heat pump for greenhouses in northern Japan. Energy 2013, 63, 387-399. [CrossRef]

20. Hu, B.; Li, Y.; Mu, B.; Wang, S.; Seem, J.E.; Cao, F. Extremum seeking control for efficient operation of hybrid ground source heat pump system. Renew. Energy 2016, 86, 332-334. [CrossRef]

21. Emmi, G.; Zarrella, A.; De Carli, M.; Galagaro, A. An analysis of solar assisted ground source heat pump in cold climates. Energy Convers. Manag. 2015, 106, 660-675. [CrossRef]

22. Biglarian, H.; Abbaspour, M.; Hassan Saidi, M. Evaluation of a transient borehole heat exchanger model in dynamic simulation of a ground source heat pump system. Energy 2018, 147, 81-93. [CrossRef]

23. Luo, J.; Rohn, J.; Bayer, M.; Priess, A. Thermal Efficiency Comparison of Borehole Heat Exchangers with Different Drillhole Diameters. Energies 2013, 6, 4187-4206. [CrossRef]

24. The Mathworks Inc. Matlab and Statistics Toolbox Release 2018a; The Mathworks Inc.: Natick, MA, USA, 2018.

25. Lemmon, E.W.; Bell, I.H.; Huber, M.L.; McLinden, M.O. NIST Standard Reference Database 23, Reference Fluid Thermodynamic and Transport Properties (REFPROP), version 10.0; National Institute of Standards and Technology: Gaithersburg, MD, USA, 2018. 
26. Pham, H.M.; Monnier, K. Interim and Long-Term Low-GWP-Refrigerant Solutions for Air Conditioning. In Proceedings of the International Refrigeration and Air Conditioning Conference at Purdue, West Lafayette, IN, USA, 11-14 July 2016.

27. ASHRAE. ANSI/ASHRAE Standard 34-2016, Designation and Safety Classification of Refrigerants; ASHRAE: Atlanta, GA, USA, 2016.

28. Sarbu, I.; Sebarchievici, C. Using Ground-Source Heat Pump Systems for Heating/Cooling of Buildings. In Advances in Geothermal Energy; InTechOpen: London, UK, 2016.

29. Capozza, A.; De Carli, M.; Zarrella, A. Design of borehole heat exchangers for ground-source heat pumps: A literature review, methodology comparison and analysis on the penalty temperature. Energy Build. 2012, 55, 369-379. [CrossRef]

30. Melinder, A. Properties of Secondary Working Fluids for Indirect Systems (Secondary Refrigerants or Coolants, Heat Transfer Fluids); International Institute of Refrigeration: Paris, France, 2010.

31. Wu, W.; Zaho, L.; Ho, T. Experimental investigation on pinch points and maximum temperature differences in a horizontal tube-in-tube evaporator using zeotropic refrigerants. Energy Convers. Manage. 2012, 56, $22-31$. [CrossRef]

32. Venkatarathnam, G.; Mokashi, G.; Murthy, S.S. Occurence of pinch points in condensers and evaporators for zeotropic refrigerant mixtures. Int. J. Refrig. 1996, 19, 361-368. [CrossRef]

33. Bitzer software v6.9.1.2074; Bitzer Kuhlmaschinenbau GmbH, 2013-2018. Available online: https://www. bitzer.de/websoftware/ (accessed on 4 February 2019).

34. Minh, N.Q.; Hewitt, N.J.; Eames, P.C. Improved Vapour Compression Refrigeration Cycles: Literature Review and their Applications to Heat Pumps. In Proceedings of the International Refrigeration and Air Conditioning Conference at Purdue, West Lafayette, IN, USA, 11-14 July 2016.

35. Babatunde, A.F.; Sunday, O.O. A Review of Working Fluids for Organic Rankine Cycle (ORC) Applications. Mater. Sci. Eng. 2018, 413, 012019. [CrossRef]

36. Domanski, P.A.; Didion, D.A.; Doyle, J.P. Evaluation of suction-line/liquid-line heat exchange in the refrigeration cycle. Int. J. Refrig. 1994, 17, 487-493. [CrossRef]

37. Borel, L.; Favrat, D. Thermodynamique et Energetique: de L'energie a L'exergie, Vol. 1 and 2; EPFL-PPUR: Lausanne, Switzerland, 2005.

(C) 2019 by the authors. Licensee MDPI, Basel, Switzerland. This article is an open access article distributed under the terms and conditions of the Creative Commons Attribution (CC BY) license (http://creativecommons.org/licenses/by/4.0/). 